This paper reports a study into the possibility of applying a simplified approach, recommended by standards for conventional steel beams, to determine the heating temperature under the conditions of a fire in relation to steel I-beams with a corrugated wall. The research is predetermined by the limitation of methods that make it possible to determine the heating temperature of this type of beam in a fire using engineering methods with a small amount of calculations.

Technical data on steel beams with cladding have been considered for calculation, the features of heat impact of fire on them have been analyzed, a calculation procedure has been devised, the estimation schemes have been built, and the calculations have been performed. Data on the temperature distribution in the cross-sections of beams with and without cladding were obtained by using a simplified method recommended by standards and the refined method based on a finite-element method.

Mathematical models have been constructed for calculations that describe the effect of a standard temperature regime of fire on the distribution of temperature in each minute in the cross-sections of steel beams with and without cladding. The models have been described on the basis of the differential equation of thermal conductivity, boundary conditions of the third kind, which take into consideration convective and radiant heat transfer.

It was established that the mineral wool cladding of the beam with a corrugated wall is a reliable fire protection agent. The heating temperature of the beam does not reach a critical value of $500^{\circ} \mathrm{C}$ in 60 minutes, which provides the class of this beam with the most stringent requirements for its fire resistance in accordance with the classification in line with the acting norms in Ukraine.

The simplified method, recommended by the current standards of the European Union and Ukraine, could be effectively used to analyze the fire resistance of these beams and is the basis of the procedure for the estimated assessment of the fire resistance of these structures

Keywords: steel beam with corrugated wall, standard temperature regime, temperature distributions

\title{
THERMAL EFFECT OF A FIRE ON A STEEL BEAM WITH CORRUGATED WALL WITH FIREPROOF MINERAL- WOOL CLADDING
}

\author{
Valeria Nekora \\ Senior Researcher \\ Sector of Fire Safety and Technology \\ Center of Fire Protection Research
}

Institute of Public Administration and Research in Civil Protection Vyshhorodska str., 21, Kyiv, Ukraine, 04074

Stanislav Sidnei

Corresponding author

$\mathrm{PhD}$, Associate Professor*

E-mail: sidney-1980@ukr.net

Taras Shnal

Doctor of Technical Sciences, Associate Professor

Department of Building Constructions and Bridges

Lviv Polytechnic National University

Stepana Bandery str., 12, Lviv, Ukraine, 79013

O Iga Nekora

$\mathrm{PhD}$, Senior Researcher, Leading Researcher Department of Organization of Scientific Activities**

L ud mila Lavrinenko

$\mathrm{PhD}$, Associate Professor

Department of Metal and Wooden Structures

Kyiv National University of Construction and Architecture

Povitroflotskyi ave., 31, Kyiv, Ukraine, 03037

Serhii Pozdieiev

Doctor of Technical Sciences, Professor, Chief Researcher* *Department of Safety of Construction and Occupational Safety** **Cherkasy Institute of Fire Safety named after Chornobyl Heroes of National University of Civil Protection of Ukraine Onoprienka str., 8, Cherkasy, Ukraine, 18034
Received date 30.08.2021

Accepted date 11.10.2021 Published date 29.10.2021

\begin{abstract}
How to Cite: Nekora, V., Sidnei, S., Shnal, T., Nekora, O., Lavrinenko, L., Pozdieiev, S. (2021). Thermal effect of a fire on a steel beam with corrugated wall with fireproof mineral-wool cladding. Eastern-European Journal of Enterprise Technologies, 5 (1 (113)), 24-32. doi: https://doi.org/10.15587/1729-4061.2021.241268
\end{abstract}

\section{Introduction}

Experience in the use of steel structures indicates significant advantages of this class of building structures, in particular steel beams. The high strength and rigidity of these structures with a relatively small mass make them alternative-free when erecting buildings with long distances between supports. Such construction objects include industrial, commercial, exhibition, warehouse, and other premises. According to modern approaches, the structural cross-section of steel beams is improved in order to reduce their mass while maintaining their strength and rigidity; however, beams with the latest design solutions need further research in order to study aspects of their behavior in emergency and non-standard situations, including those related to fires [1]. 
One of these types of modern structural solutions, which makes it possible to reduce their mass while maintaining strength, rigidity, and local stability, is represented by I-beams with a corrugated wall that has a longitudinal sinusoid profile (SIN-beams). Such a SIN-beam is a successful engineering solution for metal frames with medium and long distances between supports, the size of which can be up to $80 \mathrm{~m}$. Steel beams with a corrugated wall can act as runs, crossbars, columns for frames [2]. At the same time, their peculiarity in the form of a profiled wall makes it possible to increase the local cross-section stability, which ensures their maximum bearing capacity with a relatively small natural weight and cross-sectional height. The advantages and disadvantages of steel beams with corrugated walls are described in detail in work [3]. Among the main advantages, it should be additionally noted that the profiled wall of the beam allows one not to use additional stiffeners and, in combination, reduce the complexity of manufacturing, installation, as well as cost [4]. However, their wide application for the construction of steel frames requires establishing the level of their safety in emergencies, of which fires are traditionally the most dangerous.

Methods of fire resistance analysis have undergone significant development, which has been used to compile normative documentation, which provides scientifically based calculation methods for assessing fire resistance. Thus, the estimation assessment of the fire resistance of steel beams should be carried out using the basic provisions and recommendations contained in the norms by United Europe, implemented in the regulatory framework, given in work [5]. However, the recommendations lack data on the methods of estimation evaluation of steel beams with corrugated walls and the correctness of the use of conventional approaches. This can also be traced by the results reported in work [6].

A separate aspect associated with the estimation assessment of fire resistance of this type of beams is the use of modern fire protection systems and, in particular, systems based on mineral-wool fire-protection cladding as one of the most effective ones.

Our review revealed the lack of information on the possibility to apply the standard approach recommended in [4] for conventional steel beams when determining the heating temperature of I-beams with corrugated walls in the case of a fire. Resolving this issue is relevant to form the basis for the methodological procedure of the estimation assessment of fire resistance of steel beams with corrugated walls by engineering simplified methods.

\section{Literature review and problem statement}

Among the methods for assessing the fire resistance of building structures and, accordingly, steel beams, an experimental method of fire tests is considered reliable and appropriate. The method is implemented at special installations that combine thermal and power effects on the structures they experience in a fire and include a fire furnace and a power drive. The tests are carried out at specialized testing laboratories with appropriate equipment and state certification. The method of fire tests, in accordance with [7], is implemented by creating a temperature regime that reproduces the thermal impact of a fire when the sample is heated, the dimensions of which fully or partially correspond to the dimensions of the actual element. The basic principles of testing, in general, are described. A more detailed description of the main aspects of beam fire tests is given in [8]; for testing columns - in work [9]. This temperature regime is determined by the standard temperature curve of a fire corresponding to a logarithmic dependence. The criterion for the onset of the maximum state of fire resistance loss in terms of the bearing capacity for beams is to achieve the maximum deflection of critical values, which are determined by the procedure given in [7]. The main disadvantages of the experimental method are high cost and labor intensity. In addition, when applying this approach, it is impossible to reproduce all types of boundary conditions for real elements of building structures.

Along with the experimental method of fire tests, the use of estimation methods has become common in order to assess the fire resistance of steel beams [5]. The main recommendations for the application of this approach are contained in the regulatory documents of the United Europe, for example in [6]. The advantages of those methods include sufficient flexibility, the ability to take into consideration the entire variety of steel grades, from which the studied beams are made, various geometric sizes of structures, and various types of fireproof materials. At the same time, those methods are less time-consuming and costly compared to experimental methods.

The task of estimation assessment of fire resistance is typically divided into two separate tasks - thermal and mechanical. To resolve the thermal issue, there are two main approaches - simplified and refined. The simplified approach is described in detail in [10]. With a simplified approach, as shown in [11], recurrent formulas are used to determine the temperature of heating the cross-section of steel beams at each time of exposure to the standard fire temperature for fireproof/non-fireproof steel beams. This approach was applied in work [12]; it was established that for beams without fire protection, its use is effective. However, it should be noted that the information on the correctness of this approach for fireproof steel beams is limited and this is a matter of a separate scientific study.

Under the refined approach to resolving the thermal issue, a universal theoretical method is employed, based on the use of the differential non-stationary equation of thermal conductivity [13]. This approach is widely used and its application is described in detail in [14]. The main features of this method are the use of boundary conditions of the third kind when stating a compatible problem and using temperature-dependent thermal-physical characteristics of steel and fire-protective materials.

Paper [11] gives a large amount of data on the dependences of thermal-physical characteristics of fireproof materials on the temperature of their heating, procedures to determine them using an experimental-estimation method. The assessment of the reliability of the obtained results employing these characteristics is given in [12] while paper [15] reports a general approach when applying these data for the estimation assessment of fire resistance. At the same time, there is no single systematic procedure for applying the refined approach to determining the temperature in steel beams with a corrugated wall in the presence of fire protection. Article [16] provides several separate considerations on the application of a variety of structural models as part of the concept of ensuring fire safety for buildings in the future.

Paper [1] considers the structural features of steel beams with a corrugated wall; the main recommendations for predicting their behavior under load under normal conditions are given in the norms in [4]. The main provisions of the 
design calculation of such beams are given but there are no recommendations for determining their fire resistance limit. At the same time, in work [12], which reports a study into such beams with fire protection cladding for fire resistance, the practical aspect of the estimation fire resistance assessment is insufficiently disclosed, taking into consideration the determining of belonging to the designated fire resistance class. Effective practical approaches are used in work [16] but they have no reference to normalized methods for calculating steel structures for fire resistance [6]. In addition, those works do not cover the results of studying the fire of steel beams with a corrugated wall using fire protection and without it with a follow-up comparison of results.

Based on a normalized approach, work [6] recommended a procedure to tackle the mechanical problem of design when assessing fire resistance under the influence of the standard temperature of fire on a beam with a flat wall. However, in the case of beams with a corrugated wall, this procedure can produce unpredictable results. The mathematical model for solving the mechanical problem given in paper [6], based on standards recommendations, considers changes in the mechanical properties of steel when the temperature changes. At the same time, the state of failure of the beam is predicted by comparing the change in its resistance under the influence of temperature and active load. This model applies to the assumption of uniform temperature distribution along the cross-section of the steel beam. In this case, the calculation for strength under fire conditions for beams is carried out according to the formulas given in the norms from [5]. Thus, when solving a mechanical problem, the resistance of the bending and shear of the beam at the appropriate temperature of its heating in case of fire is calculated, which is taken into consideration by the appropriate coefficients for reducing the mechanical characteristics of steel. This procedure is used only for beams with flat walls.

It should be noted that work [10] also did not pay attention to the comparative analysis of the behavior of flat-wall steel beams and steel beams with a corrugated wall under the conditions of high-temperature heating in the event of a fire.

For such a comparative analysis, experiments were carried out, the example of which is a large-scale test carried out by Czech specialists [12]. During the test, a fire was initiated and investigated in a building with a steel frame, among the elements of which there were two beams with corrugated walls. As a result of the experiment, a noticeable discrepancy was revealed in the results obtained, compared to the estimation results derived by using the recommended norms described in work [6]. The temperatures determined during the experiment were higher than the estimation temperatures, and their distribution by the cross-section of the beam was noticeably different from the theoretical one and was uneven. There has also been assumption about the impact of flexibility on the uneven distribution. The model did not provide apt forecasts for the temperature of the shelves, which grew slower than the temperature of the wall.

In work [17], to ensure the required fire resistance, an additional increase in wall thickness is proposed, not related to the provision of bearing capacity.

Our review shows that even though the aspects of the behavior of I-beams with corrugated walls under normal conditions and fire conditions are sufficiently revealed in works by many researchers but, to determine the heating temperature, the cited studies propose a method based on solving a thermal conductivity problem, based on the numerical methods of approximation of the non-stationary equation of thermal conductivity. This method requires a significant amount of calculations. However, to determine the temperature in the beams of this type, the possibility of using a simplified standard approach remains uncertain.

\section{The aim and objectives of the study}

The purpose of this work is to determine a change in the distribution of temperature in the cross-sections of steel beams with corrugated walls with fire protection and without it under the conditions of heat exposure to fire using a simplified standard method recommended for conventional steel beams, and a general theoretical approach based on solving the non-stationary thermal conductivity equation. Comparative analysis of the obtained results would make it possible to establish the possibility of using a simplified standard method for determining the temperature in steel beams with corrugated walls under the conditions of a fire. That, in turn, could serve as a scientific basis for the development and improvement of the methodological base for the estimation assessment of fire resistance of this type of beam.

To accomplish the aim, the following tasks have been set:

- to devise a procedure for determining the temperature in the cross-section of a steel beam with a corrugated wall with a mineral-wool fireproof cladding according to the simplified method under the influence of the standard fire temperature over the period of 60 minutes;

- to devise a procedure and calculate temperature distributions in steel I-beams with corrugated walls with and without fire protection under the influence of the standard fire temperature regime using a general theoretical approach;

- to investigate the nature of heating steel I-beams with corrugated walls of the sinusoidal profile, depending on their structural features and the presence of fire protection; to perform a comparative analysis of data obtained from the simplified and refined approaches.

\section{The study materials and methods}

The beams under study are part of a solid frame but, according to the simplified approach $[10,11]$, only their cross-section is considered and, according to the refined approach, a small fragment of the beam is considered. According to this approach, a calculation procedure was devised that has the following provisions.

At the first stage, a simplified approach is used to calculate the temperature in the cross-section of a steel beam with a corrugated wall with and without fire protection, based on the use of recommendations of norms [5,6] for calculating ordinary I-beams. According to this approach, the following formula is used for a beam without fire protection to calculate the temperature in its cross-section:

$$
\Delta \theta_{a, t}=k_{s h} \cdot \frac{A_{m}}{V \cdot c_{a} \rho_{a}} \dot{h}_{n e t} \Delta t,
$$

where $k_{s h}=1$ is the adjustment coefficient, taking into consideration the effect of the effect of beam shading by other structures; $h_{\text {net }}$ is the estimated value of the total specific heat flow, $\mathrm{W} / \mathrm{m}^{2} ; c_{a}$ and $\rho_{a}$ are, respectively, the specific heat capacity $\left(\mathrm{J} /\left(\mathrm{kg}^{\circ} \mathrm{C}\right)\right)$ and density of steel $\left(\mathrm{kg} / \mathrm{m}^{3}\right)$. 
The estimated value of the total specific heat flow is determined from the following formula [6]:

$$
h_{n e t}=\alpha_{c} \cdot\left(\theta_{g}-\theta_{m}\right)+\Phi \cdot \varepsilon_{m} \cdot \varepsilon_{f} \cdot \sigma \cdot\left(\left(\theta_{g}+273\right)^{4}-\left(\theta_{m}+273\right)^{4}\right),
$$

where $\theta_{g}$ is the temperature in a fire near a beam, ${ }^{\circ} \mathrm{C} ; \theta_{m}$ is the temperature of a steel beam, ${ }^{\circ} \mathrm{C} ; \alpha_{c}=25$ is the heat transfer coefficient for convective heat exchange, $\mathrm{W} \cdot \mathrm{m}^{-2} \cdot \mathrm{K}^{-1} ; \Phi=1$ is the steel beam irradiation form-factor; $\boldsymbol{\varepsilon}_{m}$ is the degree of blackness of the surface of a steel beam; $\varepsilon_{f}=1$ is the degree of blackness of radiation of the gas environment of fire; $\sigma=5,67 \cdot 10^{-8} \mathrm{~W} \cdot \mathrm{m}^{-2} \cdot \mathrm{K}^{-4}$ is the Stefan-Boltzmann constant.

For beams with fire protection, the following formula recommended in norms [6] is used:

$$
\begin{aligned}
& \Delta \theta_{a, t}=\frac{\lambda_{P} A_{P}}{V d_{P} c_{a} \rho_{a}} \cdot \frac{\left(\theta_{g, t}-\theta_{a, t}\right)}{(1+\varphi / 3)} \cdot \Delta t-\left(e^{\varphi / 10}-1\right) \cdot \Delta \theta_{g, t}, \\
& \left(\Delta \theta_{a, t} \geq 0 \text { at } \Delta \theta_{g, t}>0\right),
\end{aligned}
$$

where the coefficient:

$$
\varphi=\frac{c_{P} \rho_{P}}{c_{a} \rho_{a}} \cdot d_{P} A_{P} / V
$$

where $A_{p} / V$ is the coefficient of a beam cross-section with mineral-wool fireproof cladding; $c_{p}=1000$ is the specific heat capacity of mineral-wool plate $\mathrm{J} /\left(\mathrm{kg}^{\circ} \mathrm{C}\right) ; d_{p}$ is the thickness of a mineral-wool plate, $\mathrm{m} ; \Delta t=30 \mathrm{~s}$ is the step in time; $\theta_{a, t}$ is the value of steel temperature at the current time step, ${ }^{\circ} \mathrm{C}$; $\theta_{g, t}$ is the temperature in the room with fire at the current time step, ${ }^{\circ} \mathrm{C} ; \Delta \theta_{g, t}$ is the increase in room temperature with fire at the current time step, ${ }^{\circ} \mathrm{C} ; \lambda_{p}$ is the thermal conductivity coefficient of a mineral-wool plate, $\mathrm{W} /\left(\mathrm{m}^{\circ} \mathrm{C}\right) ; \rho_{p}$ is the density of a mineral-wool plate, $\mathrm{kg} / \mathrm{m}^{3}$.

A universal theoretical approach was used to calculate a temperature distribution in steel beams with a corrugated wall with and without fire protection. It is based on the numerical solution to the non-stationary differential equation of thermal conductivity using the method of finite elements in accordance with the results of the research given in works $[10,13,17]$. The main components of the mathematical model used in the calculations are given in Table 1 .

Table 1

Basic mathematical models for solving the thermal problem for a steel beam with a corrugated wall according to the refined method

\begin{tabular}{|l|l|}
\hline $\begin{array}{c}\text { Components of the } \\
\text { mathematical model }\end{array}$ & \multicolumn{1}{|c|}{ Implementation technique } \\
\hline Thermal conductivity & $\begin{array}{l}\text { Differential non-stationary equation of ther- } \\
\text { mal conductivity with numerical approxima- } \\
\text { tion by the method of finite elements }\end{array}$ \\
\hline Boundary conditions & Boundary conditions of the third kind \\
\hline Physical nonlinearity & Newton-Rafson iterative method \\
\hline $\begin{array}{l}\text { Thermophysical } \\
\text { characteristics of steel }\end{array}$ & $\begin{array}{l}\text { Temperature dependences of thermal con- } \\
\text { ductivity coefficient, specific heat capacity, } \\
\text { and density according to the recommenda- } \\
\text { tions of norms [6, 7] }\end{array}$ \\
\hline $\begin{array}{l}\text { Parameters of } \\
\text { boundary conditions }\end{array}$ & $\begin{array}{l}\text { Parameters in accordance with the recom- } \\
\text { mendations of norms [6, 7] }\end{array}$ \\
\hline
\end{tabular}

During the calculation in our study, a steel beam with a corrugated wall with a sinusoidal profile, also called SIN- beam, was selected. Beam with such parameters is most common among beams of this type [1-4]. Fig. 1 shows the structural scheme of the examined steel beam with a corrugated wall.

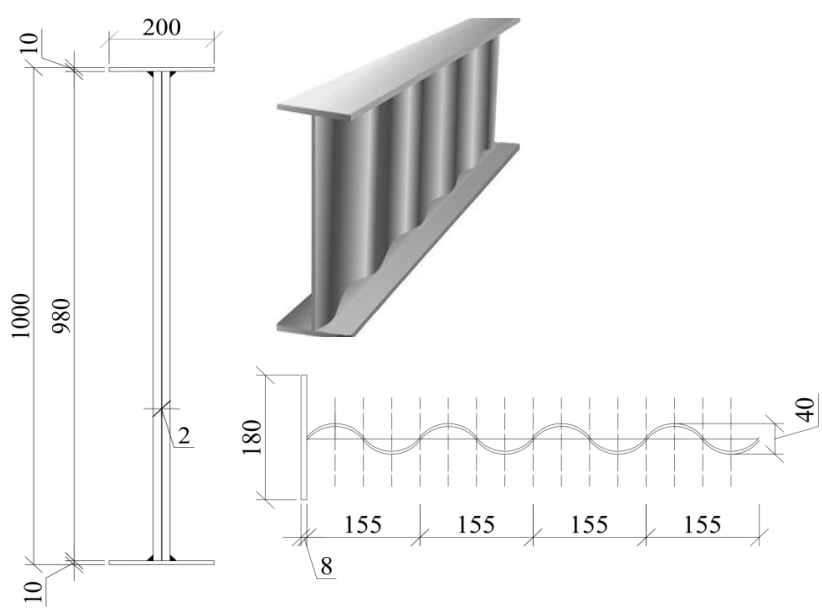

Fig. 1. Structure of steel SIN-beam with a corrugated wall

The main design parameters of the steel beam and mineral-wool cladding are given in Table 2. Fig. 2 shows the relevant structural schemes of steel beams with a fire impact scheme.

The main thermal-physical characteristics of materials and initial data on the setting of the thermal problem, which are necessary for calculations, are given in Table 3 . The thermal-physical characteristics of steel were adopted in accordance with the recommendations of norms [5,6]. The thermophysical properties of mineral-wool material were accepted taking into consideration the data given in the technical regulations [11,12].

The geometrical characteristics of steel beam cross-sections, which are necessary when applying a simplified approach, are given in Table 4.

We determined the cross-section coefficient $A_{p} / V$ for the first type of steel beam with a corrugated wall taking into consideration the increase in the heating surface due to the wavy surface of the corrugated wall of the beam and the

\begin{tabular}{|c|c|c|c|}
\hline Beam cross-section geometry & $\begin{array}{l}\text { Desig- } \\
\text { nations }\end{array}$ & Value & $\begin{array}{l}\text { Measure- } \\
\text { ment unit }\end{array}$ \\
\hline - width & $b$ & 200 & \multirow{8}{*}{$\mathrm{mm}$} \\
\hline - shelf width & $t_{f}$ & 10 & \\
\hline - height & $h$ & 1,000 & \\
\hline - wall height & $t_{w}$ & 2 & \\
\hline $\begin{array}{l}\text { - deployed half-wave length of } \\
\text { corrugations }\end{array}$ & $s$ & 161 & \\
\hline - wave length & $m$ & 155 & \\
\hline - wave height & $f$ & 40 & \\
\hline - beam length & $l$ & 12,000 & \\
\hline Steel density & $\rho_{a}$ & 7,850 & $\mathrm{~kg} / \mathrm{m}^{3}$ \\
\hline Mineral-wool plate thickness & $d_{p}$ & 25 & $\mathrm{~mm}$ \\
\hline
\end{tabular}
three-sided impact of the fire. This is shown in Fig. 3.

Table 2

The main parameters of the steel beam overlap 


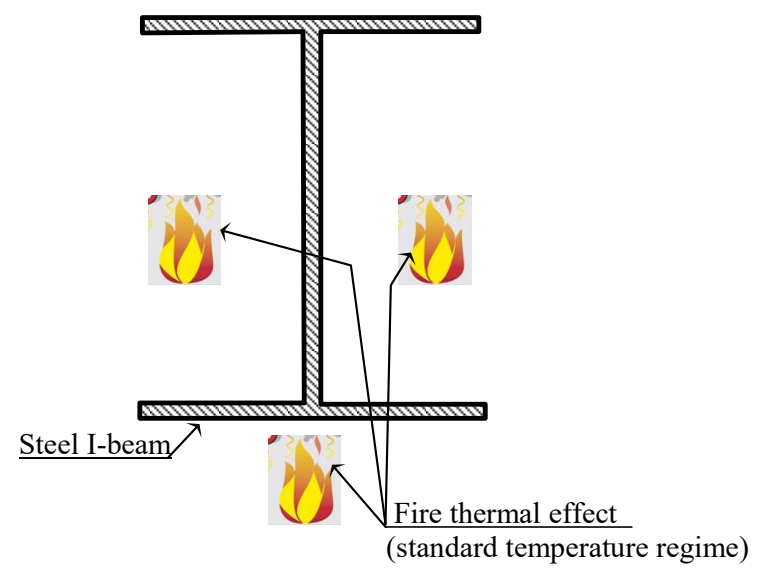

$a$

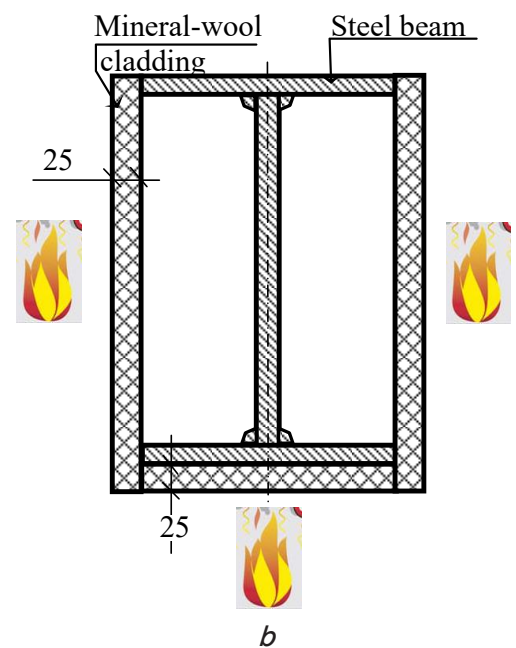

Fig. 2. Schematic of heat exposure of fire on the two types of examined steel beams with corrugated walls: $a$ - without fire protection; $b$ - with fire protection based on mineral-wool plates

Table 3

Thermal-physical characteristics of steel

\begin{tabular}{|c|c|c|}
\hline Thermal conductivity coefficient, $\lambda(\theta), \mathrm{W} /\left(\mathrm{m} \cdot{ }^{\circ} \mathrm{C}\right)$ & Specific heat capacity, $c_{p}(\theta), \mathrm{J} /\left(\mathrm{m}^{3} \cdot{ }^{\circ} \mathrm{C}\right)$ & Density, $\mathrm{kg} / \mathrm{m}^{3}$ \\
\hline \multicolumn{3}{|c|}{ Structural steel } \\
\hline $\begin{array}{c}54-3.33 \cdot 10^{-2} \theta \text { at } 20^{\circ} \mathrm{C} \leq \theta \leq 800^{\circ} \mathrm{C} \text {, } \\
27.3 \text { at } \theta>800{ }^{\circ} \mathrm{C}\end{array}$ & $\begin{array}{c}425+0.773 \theta-1,69 \cdot 10^{-2} \theta^{2}+2.22 \cdot 10^{-6} \theta^{3} \text { at } 20^{\circ} \mathrm{C} \leq \theta \leq 600^{\circ} \mathrm{C}, \\
666-13,002 /(\theta-738) \text { at } 6000^{\circ} \mathrm{C}<\theta \leq 735^{\circ} \mathrm{C}, \\
545+17,820 /(\theta-731) \text { at } 735^{\circ} \mathrm{C}<\theta \leq 900^{\circ} \mathrm{C}, \\
650 \text { at } 900{ }^{\circ} \mathrm{C}<\theta \leq 1,200^{\circ} \mathrm{C}\end{array}$ & 7,850 \\
\hline \multicolumn{3}{|c|}{ Mineral wool [1] } \\
\hline 0.04 & 1,000 & 200 \\
\hline
\end{tabular}

Table 4

The main characteristics of steel beam cross-sections for thermal calculation

\begin{tabular}{|c|c|c|c|}
\hline Parameter & $\begin{array}{l}\text { Desig- } \\
\text { nation }\end{array}$ & $\begin{array}{l}\text { Measure- } \\
\text { ment unit }\end{array}$ & Value \\
\hline \multicolumn{4}{|c|}{ Steel beam with corrugated wall without fire protection } \\
\hline Specific volume of steel beam & $V$ & $\mathrm{~m}^{3} / \mathrm{m}$ & 0.072 \\
\hline $\begin{array}{l}\text { The specific area of the heating } \\
\text { surface of the beam }\end{array}$ & $A_{p}$ & $\mathrm{~m}^{2} / \mathrm{m}$ & 31.418 \\
\hline $\begin{array}{l}\text { The thickness of the fire-retardant } \\
\text { lining of the beam }\end{array}$ & $d_{p}$ & $\mathrm{~m}$ & 0 \\
\hline $\begin{array}{l}\text { Beam cross-sectional ratio (ratio } \\
\text { of specific area to specific volume) }\end{array}$ & $A_{p} / V$ & $\mathrm{~m}^{-1}$ & 433.605 \\
\hline Time step & $\Delta t$ & $\mathrm{~s}$ & 30 \\
\hline \multicolumn{4}{|c|}{ Steel beam with corrugated wall with fire protection } \\
\hline Specific volume of steel beam & $V$ & $\mathrm{~m}^{3} / \mathrm{m}$ & 0.072 \\
\hline $\begin{array}{l}\text { The specific area of the heating } \\
\text { surface of the beam }\end{array}$ & $A_{p}$ & $\mathrm{~m}^{2} / \mathrm{m}$ & 27.6 \\
\hline $\begin{array}{l}\text { The thickness of the fire-retardant } \\
\text { lining of the beam }\end{array}$ & $d_{p}$ & $\mathrm{~m}$ & 0.025 \\
\hline $\begin{array}{l}\text { Beam cross-sectional ratio (ratio } \\
\text { of specific area to specific volume) }\end{array}$ & $A_{p} / V$ & $\mathrm{~m}^{-1}$ & 380.909 \\
\hline Time step & $\Delta t$ & $\mathrm{~s}$ & 30 \\
\hline
\end{tabular}

To determine the cross-section coefficient of the beam with a corrugated wall while considering the variable sinusoidal configuration of its cross-section along the length, we used:

$$
\begin{aligned}
& A_{m}=\left(3 b-2 t_{w}\right) L+\left(h-2 t_{f}\right) S \\
& V=2 b t_{f} L+\left(h-2 t_{f}\right) S t_{w},
\end{aligned}
$$

where $S=2 L s / m$ is the length of the sinusoid contour of the corrugated wall, $\mathrm{m}$.

For the thermal calculation of steel beams exposed to fire by many researchers using a universal theoretical approach, when setting the thermal conductivity problem, the recommendations given in works $[5,6]$ were used.

In order to solve the problem of non-stationary thermal conductivity with the use of the finite-element method (FEM), the hexahedral finite element of the Lagrange type, the shape of which is shown in Fig. 2, was used.

Finite-element schemes of steel beams with corrugated walls with fire protection and without fire protection are shown in Fig. 4. In the diagram shown in Fig. 4, the types of materials from which steel beams and fire protection of these structures are made are marked with different colors.

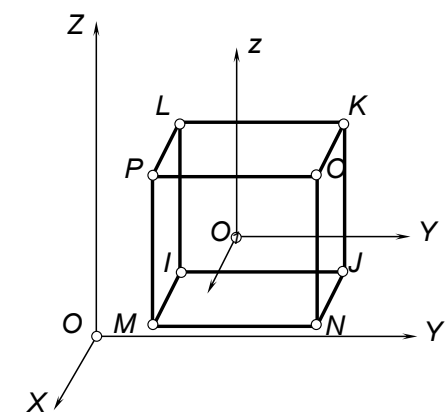

Fig. 3. Type and shape of the finite element for calculation 


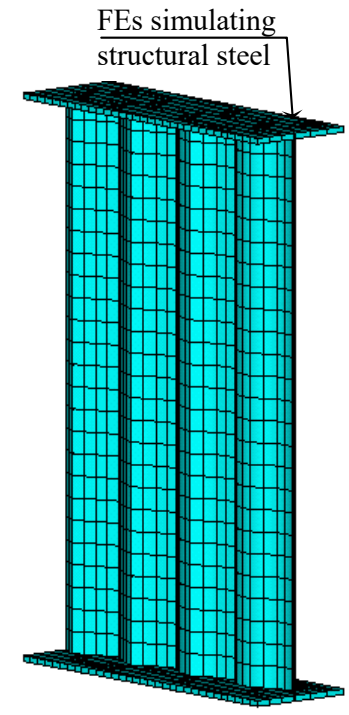

a

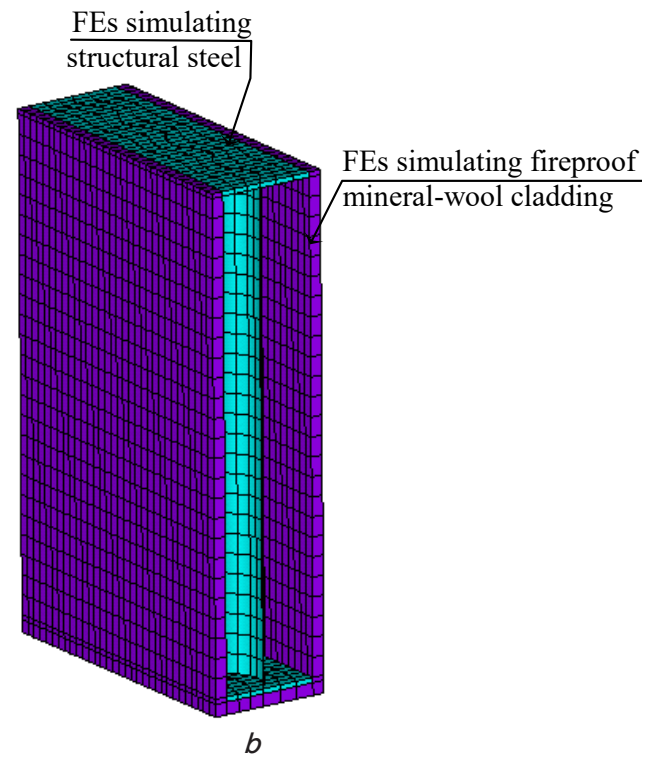

Fig. 4. Finite-element schemes of steel beams with corrugated walls: $a-$ without fire protection; $b$ - with mineral-wool fireproof cladding

A quasilinear parabolic thermal conductivity equation with boundary conditions (BCs) of kind III is used when calculating radiation and convection heat exchange with fire environment. The conditions of heat exposure from a fire correspond to the standard temperature curve (5).

The thermophysical characteristics (TPCs) of steel from which the studied corrugated beams are made are represented by appropriate thermal dependences according to [6].

The non-stationary thermal conductivity equation is solved using a finite-element method (FEM) using the ANSYS APDL software package $[10,17]$. In accordance with the recommendations of the standards presented in works [1-9], the calculations were carried out using the standard fire temperature regime, which is determined from the following formula:

$$
\theta_{p}(t)=345 \cdot \lg (8 t / 60+1)+\theta_{0},
$$

where $t$ is the time of fire impact, s; $\theta_{0}$ is the initial temperature of the medium, ${ }^{\circ} \mathrm{C} ; \theta_{0}=20^{\circ} \mathrm{C} ; \theta_{p}(t)$ is the temperature in the fire chamber of the installation to determine the limits of fire resistance of structures depending on the time $t$ of a standard test.

Using the above mathematical models, a procedure for conducting research with their use was devised. The devised procedure, when using a simplified approach, involves the following procedures:

1. Taking into consideration the geometrical characteristics, thermal properties of steel and fire-protective cladding, the necessary parameters included in expressions (1), (2) are determined.

2. By performing a step-by-step calculation, the heating temperature of the studied steel beams with corrugated walls with fire protection and without it over the time of $60 \mathrm{mi}$ nutes of exposure to the standard temperature regime of fire is determined. This time is determined by the most stringent class of fire resistance for such elements of steel structures.

The calculation procedure according to the general theoretical approach is carried out when using the following provisions and techniques:

1. Temperature calculation in the beams studied is carried out on the basis of a non-stationary quasilinear thermal conductivity equation with the temperature-dependent thermal-physical characteristics of steel and constant thermophysical characteristics of mineral-wool fire-protective cladding. The boundary problem is stated with the boundary conditions of the third kind.

2. A geometric finite-element scheme using the ANSYS APDL software package is built.

3. After adjusting the parameters of the computing process using the ANSYS APDL software package, the calculation is performed and the results are obtained at a time of 60 minutes of exposure to the standard fire temperature.

4. The possibility of using a simplified standard method for determining the temperature in steel beams with corrugated walls under fire conditions is established on the basis of a comparative analysis of the obtained results.

5. The results of studying the thermal impact of fire on steel beams with fireproof cladding and without it

5. 1. The results of calculating the beam temperature in the fire according to the simplified method

Using both approaches, the results of the calculation of temperature data in the studied steel beams with corrugated walls without fire protection and with fire protection at different points in time were obtained.

Fig. 5 shows the temperature regime of heating steel beams with corrugated walls with fire protection and without it over the control time of the fire of $60 \mathrm{~min}$.

The calculation results given in Fig. 5 show that the maximum heating temperature of a steel beam with a corrugated wall without fire protection is $946^{\circ} \mathrm{C}$, and a steel beam with a corrugated wall with fire protection is $305^{\circ} \mathrm{C}$.

If one uses a simplified idea based on the results reported in $[8,18]$, according to which the loss of fire resistance for steel structures is registered on the basis of the criterion of the occurrence of a critical temperature of $500{ }^{\circ} \mathrm{C}$, then, without the fire protection, the beam does not correspond to the class of fire resistance R60. Otherwise, when using a fire protection system based on mineral-wool cladding, the beam under study corresponds to this class of fire resistance. 

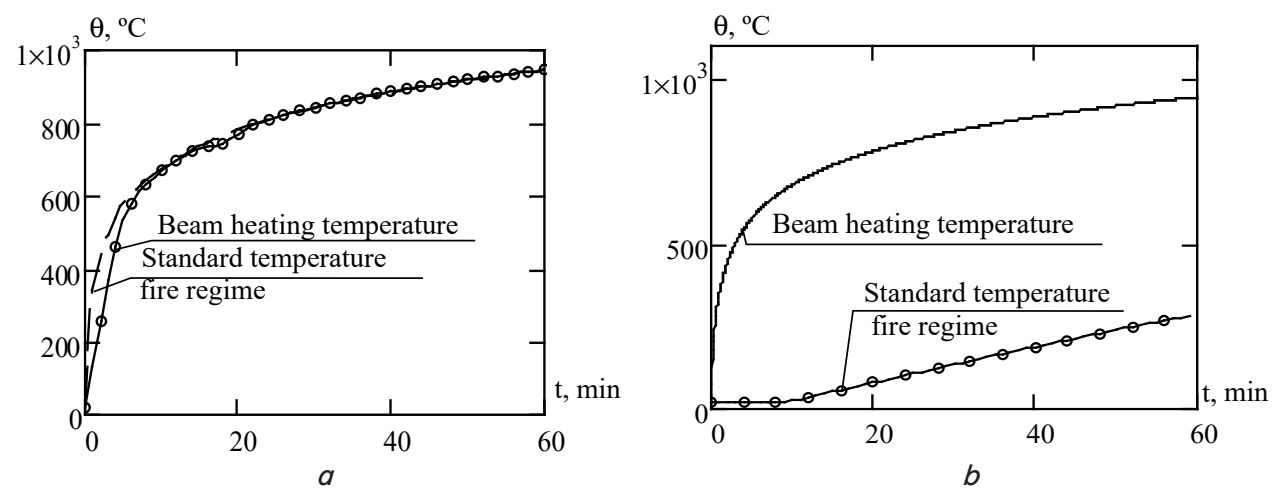

Fig. 5. Heating modes of steel beams with corrugated walls for 60 minutes at appropriate fire temperature regime: $a$ - without fire protection; $b$ - with fire protection based on mineral-wool plates

5. 2. The results of calculating the beam temperature under fire conditions using a universal theoretical approach

When applying a universal theoretical approach, temperature distribution was obtained on fragments of steel beams with corrugated walls with and without fire protection, which are shown in Fig. 6, 7.

The data given in Fig. 6, 7 show that the existing fireproof cladding leads to much less intense heating of the beam, and this, in turn, confirms the effectiveness of its use.

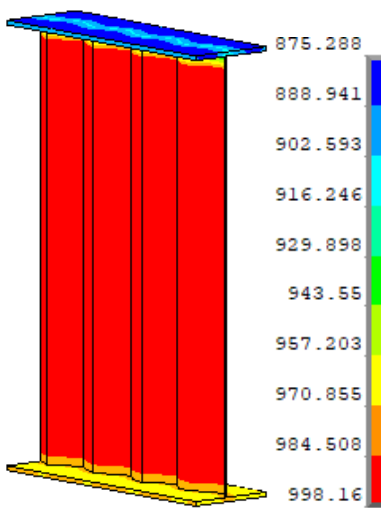

$a$

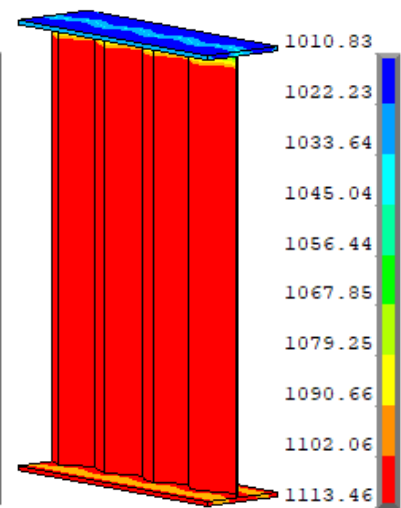

$b$
5. 3. The comparative analysis of the results of temperature calculation in a steel beam with a corrugated wall under a fire

In order to obtain more reliable data on the propagation of temperature in steel beams with corrugated walls with fire protection and without fire protection, the plots of average temperature were built (Fig. 9). The temperature indicators are registered at the inner surface in the middle of walls and shelves according to the recommendations of standards [5, 6]. The scheme for determining control points is shown in Fig. 8.

Fig. 6. Temperature distribution in a steel corrugated beam at different points in time (K): $a-15 \mathrm{~min} ; b-30 \mathrm{~min} ; c-45 \mathrm{~min} ; d-60 \mathrm{~min}$

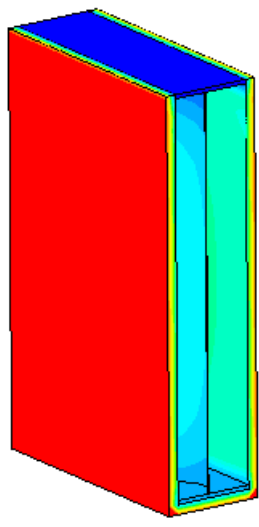

a

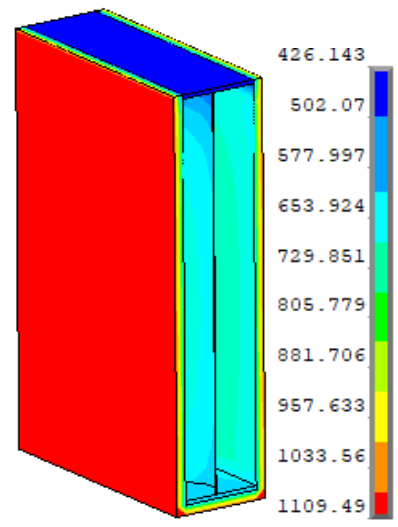

b

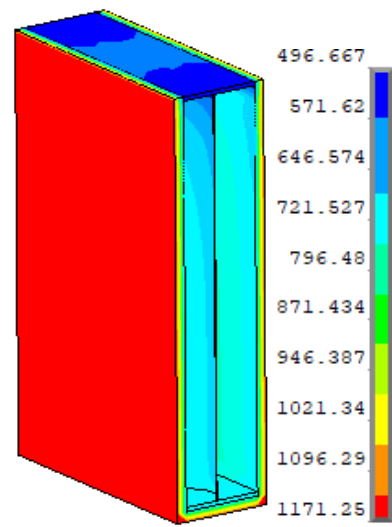

c

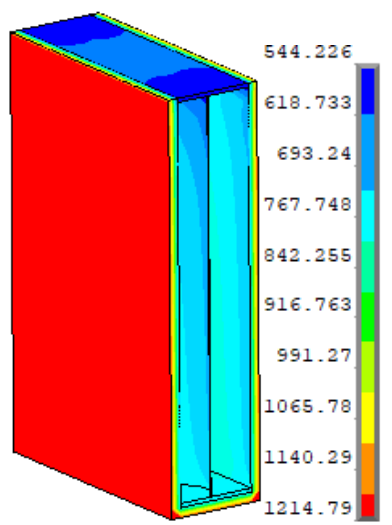

d

Fig. 7. Temperature propagation in the studied corrugated beams with mineral-wool fire-protective cladding at different points in time (K): $a-15 \mathrm{~min} ; b-30 \mathrm{~min} ; c-45 \mathrm{~min} ; d-60 \mathrm{~min}$ 


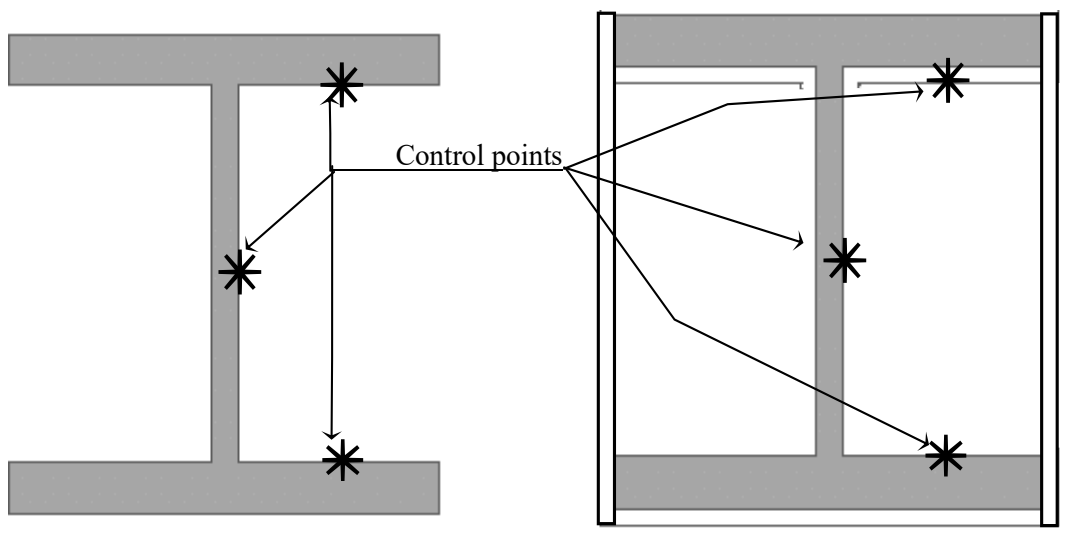

Fig. 8. Diagram of the location of control points corresponding to the position of thermocouples to control the temperature in the cross-sections of structures during tests without fire protection and with fire protection
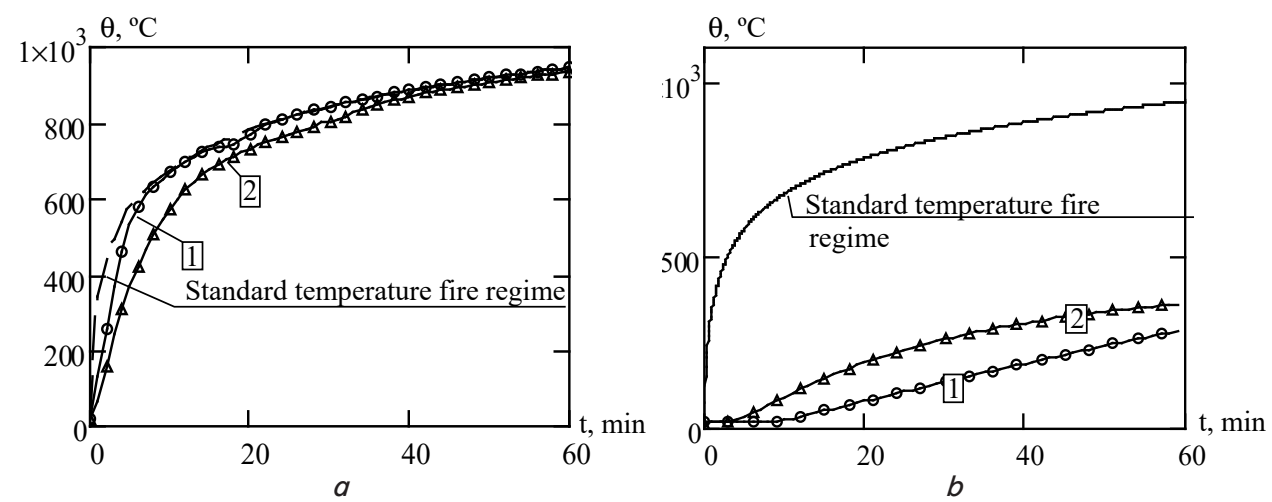

Fig. 9. Heating modes of steel beams with corrugated walls:

$a$ - without fire protection; $b$ - with fire protection over 60 minutes of the appropriate fire temperature mode;

1 - results obtained using the simplified method; 2 - results obtained using the finite-element method

As a result, we plotted temperature values, averaged by three control points, shown in Fig. 9.

In addition, Fig. 9 shows the plots of the temperature regime of heating steel beams during the control time of fire impact of 60 min, obtained as a result of the use of a generalized theoretical approach. Fig. 9, for comparison, demonstrates the plots built when applying the simplified method.

\section{Discussion of results of studying the thermal} impact of fire on steel beams with and without fire protection cladding

Studying the spread of temperature in the cross-section of the studied structures, which is shown in Fig. 6, one can see that the temperature spreads along the structures almost evenly while the distribution of temperatures along the cross-section is no more than $100^{\circ} \mathrm{C}$. At the same time, on minute 15 , the temperature reaches $600{ }^{\circ} \mathrm{C}$, which agrees with the results obtained from the simplified method.

According to the results of the analysis of the above plots in Fig. 7, it can be noted that the indicators of temperature values, which are calculated according to different methods, differ by about $150{ }^{\circ} \mathrm{C}$. This is explained by a more accurate description of heat transfer at the boundary of the estimated region. Analyzing the results obtained using the general theoretical approach for beams with fire protection, warming up occurs more intensively. In addition, such a result can be explained by greater accuracy of the mathematical heat transfer model, taking into consideration the temperature de- pendences of the thermophysical characteristics of the mineral-wool fire protection cladding, as well as heat exchange in the cavities between the structure and fire protection cladding. At the same time, both methods demonstrated, when applying the criterion of «critical temperature», $500{ }^{\circ} \mathrm{C}$ at the occurrence of fire resistance loss in terms of bearing capacity. The methods used produce the same result - without fire protection, the beam does not correspond to the fire resistance class R 60, and, when using fire protection, the required fire resistance class is provided. The results obtained during our research showed that for steel beams with corrugated walls with fire protection and without fire protection, in order to determine the heating temperature under fire conditions, it is acceptable to use a simplified engineering approach recommended by the relevant Eurocodes [15]. That means that a given simplified method of determining the temperature in the beams under study may be part of improving the methodological base for their estimation fire resistance assessment. This method is limited to only one type of fire protection systems - fireproof cladding with mineral-wool panels. However, further research could remove uncertainty about the ability to apply a given approach to other fire protection systems. The results of our study should be used in further studies when solving the problem of analysis of the stressed-strained state of steel beams with corrugated walls under fire conditions. In addition, to verify the results, appropriate fire tests of the studied beams should be carried out with the registration of the appropriate temperatures and the moment of occurrence of the maximum state of fire resistance loss in terms of bearing capacity. 


\section{Conclusions}

1. To study the distribution of temperature in the crosssection of steel beams with corrugated walls without fire protection and with fire protection, a procedure was devised, based on a simplified approach in accordance with the recommendations of Eurocodes; the results have been compared. The high efficiency of fireproof cladding based on mineral-wool plates has been shown, which blocks the heating of the beam to a critical temperature of $500{ }^{\circ} \mathrm{C}$, which significantly increases the class of fire resistance of the structure.

2. A procedure for determining the temperature in the cross-section of a steel beam with a corrugated wall with mi- neral-wool fireproof cladding using a generalized theoretical approach has been devised. Based on the obtained data, it was established that the beam without fire protection does not correspond to the fire resistance class $\mathrm{R} 15$ while the presence of fire protection makes it possible to increase its fire resistance class to R 60 .

3. It has been established that the results of temperature calculation in a steel beam with a corrugated wall in the presence of fire protection and without it differ no more than by $50{ }^{\circ} \mathrm{C}$. Based on our studies, it has been shown that a given simplified method for determining the temperature in the examined beams could be part of the improvement of the methodical base for the estimation assessment of their fire resistance.

\section{References}

1. TU U V.2.6-28.1-30653953-007:2007. Balki dvutavrovye gofrirovannye oblegchennye (gofro-balki). Rekomendatsii po proektirovaniyu (chetvertaya redaktsiya) (2008). Kharkiv: AO «Metallist SMK», 97.

2. Pichugin, S. F., Chichulinm, V. P., Chichulinam, K. V., Fedorovm, B. V. (2011). Financial viability of the use of new types of light beams with the corrugated web. Zbirnyk naukovykh prats [Poltavskoho natsionalnoho tekhnichnoho universytetu im. Yu. Kondratiuka]. Ser.: Haluzeve mashynobuduvannia, budivnytstvo, 2, 149-155.

3. Raviraj, Dr. S. Design Of Beams With Corrugated Web. Built Constructions. Available at: http://www.builtconstructions.in/ OnlineMagazine/Bangalore/Pages/Design-Of-Beams-With-Corrugated-Web-310.aspx

4. Vassart, O., Zhao, B., Cajot, L.-G., Robert, F., Meyer, U., Frangi, A. (2014). Eurocodes: background \& applications. Structural Fire Design. Worked examples. Luxemburg: Publications Office of the European Union, 252. doi: http://doi.org/10.2788/85432

5. Lavrinenko, L., Nekora, V. (2020). The fire heating of steel girders with corrugated webs. Building Constructions. Theory and Practice, 6, 12-21. doi: https://doi.org/10.32347/2522-4182.6.2020.12-21

6. Vasilchenko, A., Otrosh, Y., Adamenko, N., Doronin, E., Kovalov, A. (2018). Feature of fire resistance calculation of steel structures with intumescent coating. MATEC Web of Conferences, 230, 02036. doi: https://doi.org/10.1051/matecconf/201823002036

7. Kovalov, A., Otrosh, Y., Chernenko, O., Zhuravskij, M., Anszczak, M. (2021). Modeling of Non-Stationary Heating of Steel Plates with Fire-Protective Coatings in Ansys under the Conditions of Hydrocarbon Fire Temperature Mode. Materials Science Forum, 1038, 514-523. doi: https://doi.org/10.4028/www.scientific.net/msf.1038.514

8. Vasilchenko, A., Doronin, E., Ivanov, B., Konoval, V. (2019). Effect of Residual Deformation of a Steel Column on its Fire Resistance under Combined Exposure «Explosion-Fire». Materials Science Forum, 968, 288-293. doi: https://doi.org/10.4028/ www.scientific.net/msf.968.288

9. Otrosh, Y., Surianinov, M., Golodnov, A., Starova, O. (2019). Experimental and Computer Researches of Ferroconcrete Beams at High-Temperature Influences. Materials Science Forum, 968, 355-360. doi: https://doi.org/10.4028/www.scientific.net/msf.968.355

10. Pozdieiev, S., Nuianzin, O., Borsuk, O., Nedilko, I. (2021). Research of Integrity of Fire Insulation Cladding with Mineral Wool of Steel Beam under Fire Impact. IOP Conference Series: Materials Science and Engineering, 1021, 012024. doi: https://doi.org/ $10.1088 / 1757-899 x / 1021 / 1 / 012024$

11. Pozdieiev, S., Nuianzin, O., Borsuk, O., Binetska, O., Shvydenko, A., Alimov, B. (2020). Temperature effect on the thermal-physical properties of fire-protective mineral wool cladding of steel structures under the conditions of fire resistance tests. Eastern-European Journal of Enterprise Technologies, 4 (12 (106)), 39-45. doi: https://doi.org/10.15587/1729-4061.2020.210710

12. Ilyin, N., Panfilov, D., Lukin, A. (2017). Constructive fire protection of steel corrugated beams of buildings and other structures. MATEC Web of Conferences, 106, 02014. doi: https://doi.org/10.1051/matecconf/201710602014

13. Roytman, V. M. (2001). Inzhenernye resheniya po otsenke ognestoykosti proektiruemyh i rekonstruiruemyh zdaniy. Moscow: Pozharnaya bezopasnost' i nauka, 382.

14. Perel'muter, A. V., Slivker, V. I. (2002). Raschetnye modeli sooruzheniy i vozmozhnost' ih anliza. Kyiv: Izd-vo «Stal'», 600 .

15. Lennon, T., Mur, D. B., Van, Yu. K., Beyli, K. G. (2013). Rukovodstvo dlya proektirovschikov k EN 1991-1-2:2002, EN 1992-1-2:2002, EN 1993-1-2:2002 i EN 1994-1-2:2002: spravochnik po proektirovaniyu protivopozharnoy zaschity stal'nyh, stalezhelezobetonnyh i betonnyh konstruktsiy zdaniy i sooruzheniy v sootvetstvii s Evrokodami. Moscow, 196.

16. Heinisuo, M., Laasonen, M. (2007). Product modeling, part of the fire safety concept in the future for metal structures? Conference: Advanced Research Workshop on Fire Computer Modeling. Available at: https://www.researchgate.net/publication/ 256426230_Product_modeling_part_of_the_fire_safety_concept_in_the_future_for_metal_structures

17. Lu, W., Makelainen, P. (2003). Advanced Steel Structures. Structural Fire Design. Helsinki University of Technology Laboratory of Steel Structures Publications 29. Espoo.

18. Pospelov, B., Andronov, V., Rybka, E., Samoilov, M., Krainiukov, O., Biryukov, I. et. al. (2021). Development of the method of operational forecasting of fire in the premises of objects under real conditions. Eastern-European Journal of Enterprise Technologies, 2 (10 (110)), 43-50. doi: https://doi.org/10.15587/1729-4061.2021.226692 